\title{
REALTIME BLOOD BANK DATA REPOSITORY
}

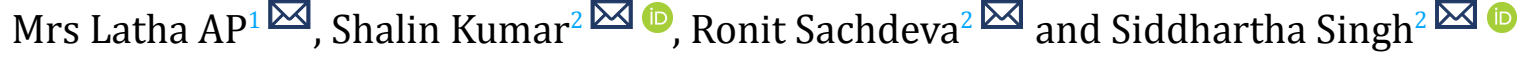 \\ ${ }^{1}$ Assistant Professor, Department of Information Science and Engineering, DSCE, Bangalore, India \\ ${ }^{2}$ Department of Information Sci0ence and Engineering, DSCE, Bangalore, India
}
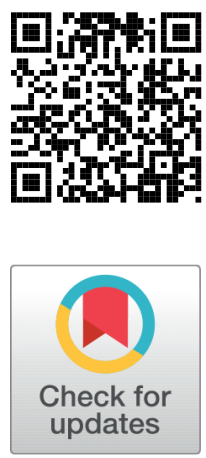

Received 5 June 2021

Accepted 20 June 2021

Published 30 June 2021

Corresponding Author

Mrs Latha AP, aplatha-ise@dayana ndasagar.edu

DOI $10.29121 /$

ijetmr.v8.i6.2021.964

Funding: This research received no specific grant from any funding agency in the public, commercial, or not-for-profit sectors.

Copyright: (C) 2021 The Author(s). This is an open access article distributed under the terms of the Creative Commons Attribution License, which permits unrestricted use, distribution, and reproduction in any medium, provided the original author and source are credited.

\section{ABSTRACT}

The real motive behind the Realtime Blood Bank Data Repository is to streamline and mechanize the way toward looking for blood if there should be an occurrence of crisis and keep up the records of blood givers, beneficiaries, blood gift projects and blood stocks in the bank. As of now, people, in general, can just think about the blood donation event occasions through traditional media means like radio, paper or TV commercials. There is no data with respect to the blood gift programs accessible on any of the gateway. With the manual archive, there are issues in dealing with the records. There is no concentrated data set of volunteer benefactors. Along these lines, it turns out to be truly dreary for an individual to look through blood if there should arise an occurrence of crisis. This task plans to mechanize the blood and contribute to the board framework in a blood donation centre to improve the record executives effectiveness because of the developed size of records of information.

Keywords: Blood Bank, Realtime Blood Bank Data Repository, Blood Donation, Hospitals, Blood Crysis, Blood Database, Blood Donation Events

\section{INTRODUCTION}

The essential structural aim is to give blood donation administration to the city as soon as possible. Real-time blood donation centre data repository is an application that is Web-based and used to store, recover, measure and break down data about the authoritative and then stock up the executives of a blood donation centre.This venture targets keeping up all the data relating to blood givers, distinctive blood bunches accessible in each blood donation centre and assisting them with overseeing in a superior manner. Venture Aim is to give straightforwardness in this field, make the interaction of acquiring blood from a blood donation centre problem-free and debasement free and make the arrangement of blood donation centre administration powerful. 
To do this we require a superior grade. Web Application to deal with those positions. Blood donation centre gift frameworks can gather blood from numerous donors in short from different sources and disperse that blood to penniless individuals who require blood. This is an electronic data set application framework that can be utilized by blood donation centres or blood focuses as a way to promote the cross country blood gift occasions to the general population and at the same time permit the medical clinics to ask for the blood. The framework keeps the record of the relative multitude of benefactors, beneficiaries, blood gift programs, and dismissed blood types.

\section{LITERATURE SURVEY}

Most blood donation centres are as yet running manual frameworks in their cycles. Thus, there is an absence of effectiveness since it is still paper-situated in gathering data about givers, inventories of blood sacks, and blood bonding administrations. The absence of appropriate documentation may jeopardize patients' well being because of the chance of polluting blood packs. Pollution happens when there is a deficient contributors' clinical history record and the blood sacks' time span of usability isn't observed as expected. Subsequently, an electronic blood donation centre administration framework may be expected to resolve these issues and issues experienced to guarantee blood bonding wellbeing.

Numerous examinations were held and led to the idea of blood donation centre, many of them worried about overseeing the records of benefactors to work with the cycles of gift, the others associated blood donation centres to one another in one framework and one information base, the rest utilized current innovation like an electronic card and standardized identification framework. Blood donation centre Information Management System is a data framework which assists with dealing with the benefactors records and patients at the blood donation centre.

It is mainly intended to recover, measure, store and dissect data which is worried about the authoritative and administration of stock inside a blood donation centre. Such sort of framework will permit the approved blood donation centre official to log in utilizing a mysterious secret phrase and effectively deal with the records of the blood donors and the patients who needs blood. Furthermore, the blood donation centre data the board framework isn't out of date to the experts; rather it assumes an extraordinary part in drawing in the contributors and different partners because of its effortlessness in the booking, and warning of gift time to the needy. A report published by Dr Sharad Maheshwari in the International Journal of Engineering Research and Application (IJERA), said that in India, the blood donation centre administration data framework MIS is a coordinated blood mechanization framework.

The electronic component which connects all the blood donation centres of each state into a solitary organization, The blood donation centre alludes to all obtaining, approval, capacity and course of different live information and data electrically 
with respect to blood gift and bonding administration. The ZNBTS aka Zambia Blood Transfusion Service with help from the International Institution for Communication and Development (IICD) has brought up an electronic framework that has digitized enlisting of the contributor and sends an SMS message to benefactors of blood advising them that they can give blood Again. In addition to that the product also makes it simpler to arrive at blood donors by registering their data and then saving it online in an information base to be opened from any office of the ZNBTS.

\section{PROBLEM STATEMENT}

The present-day situation in India is a paper-based system that is enduring lack of central data references, which results in a time-consuming process for retrieving data in addition to lack of security of data and human error which needs an alarming system to circumvent. One of the problems currently in hospitals which is very serious is the lack of blood supply during an emergency situation. The crucial need to transfer blood requires proper management to determine which blood group is available. The second problem which arises and that has led to the design of this system which in turn leads to human errors is that the vital information about the blood grouping, donor availability, tracing the data is complicated and time-consuming when it is done manually. Moreover, this system requires a lot of manpower, data is also not secure, in addition to that retrieval of data and production of reports are timeconsuming. In the past few years, India has seen an increment in the blood collection (from 9.5 million units in 2012 to 11.4 in 2017) . But still there was a shortage of about 1.95 million units of blood last year.

\section{EXISTING SYSTEM}

Various studies have been composed on the idea of blood donation centre administration frameworks with most of them commending computerization as a component of accomplishing effectiveness also, adequacy in this space accordingly not taking a gander at certain issues the framework may look due to restricted or abuse of functionalities. Pah Essah and Said Ab Rahman (2011) proposed an improvement of an administration data framework to oversee blood donation centre dependent on data of benefactor, beneficiary and blood. Their framework has three modules: the benefactor module, patient module and blood module.

Anyway, some essential issues are left to the side in this methodology, for example, who is liable for the organization of the framework. As indicated by Mailtrey D Gaijjart (2002) proposes an improvement of blood donation centre information framework as an answer for forestall close to miss occasions and improve record recovery. They contend that with computerization quick recovery of records will improve the productivity of blood donation centres activities. Akshay V Jain Khanter (2009) recommends an administration data framework application that covers a portion of 
the blood donation centre administration issues identified with a specific area. An intriguing methodology by Jeroen Benien and Hein Force (2012) is that of production network the executives for blood and blood items naming the cycle as sporadic and the interest for blood stochastic. This is of extraordinary ramifications if the administration of blood donation centres were to get compelling. At last, E. M. S. S. Ekanayaka and C. Wimaladharma (2015) fostered a blood bank's framework to accumulate all the blood givers into one spot naturally and illuminate them continually about the chances to give blood by means of an SMS to the benefactor's versatile telephone.

The following is a proposed framework that will dispose of the relative multitude of issues that the blood donation centres and board framework is confronting at present.

\section{METHODOLOGY}

The research methodology was built up by studying the problem definition, gathering data, design, and finally conclusion. The process of the blood bank requires registration of donor, information of the donor and testing, donation of blood, bloodstock management, blood screening and stock movements, and presently, there's a manual system to keep count of the records of blood screening and donor registration which features a lot of problems and errors.

Also, it has tried to gather some forms that they use in collecting information of donors. The collected data is evaluated and analyzed and then the needed information is extracted.

\section{DESIGN AND IMPLEMENTATION}

As stated in methodology, the system proposed was divided into different screens, which represent the major departments in the blood bank. The system is used to maintain the full information about blood, donor and transfusion process in the laboratories, the system uses a database which is central to store all input details including blood stock, donor information and blood group's information. The proposed UML class diagrams are: 


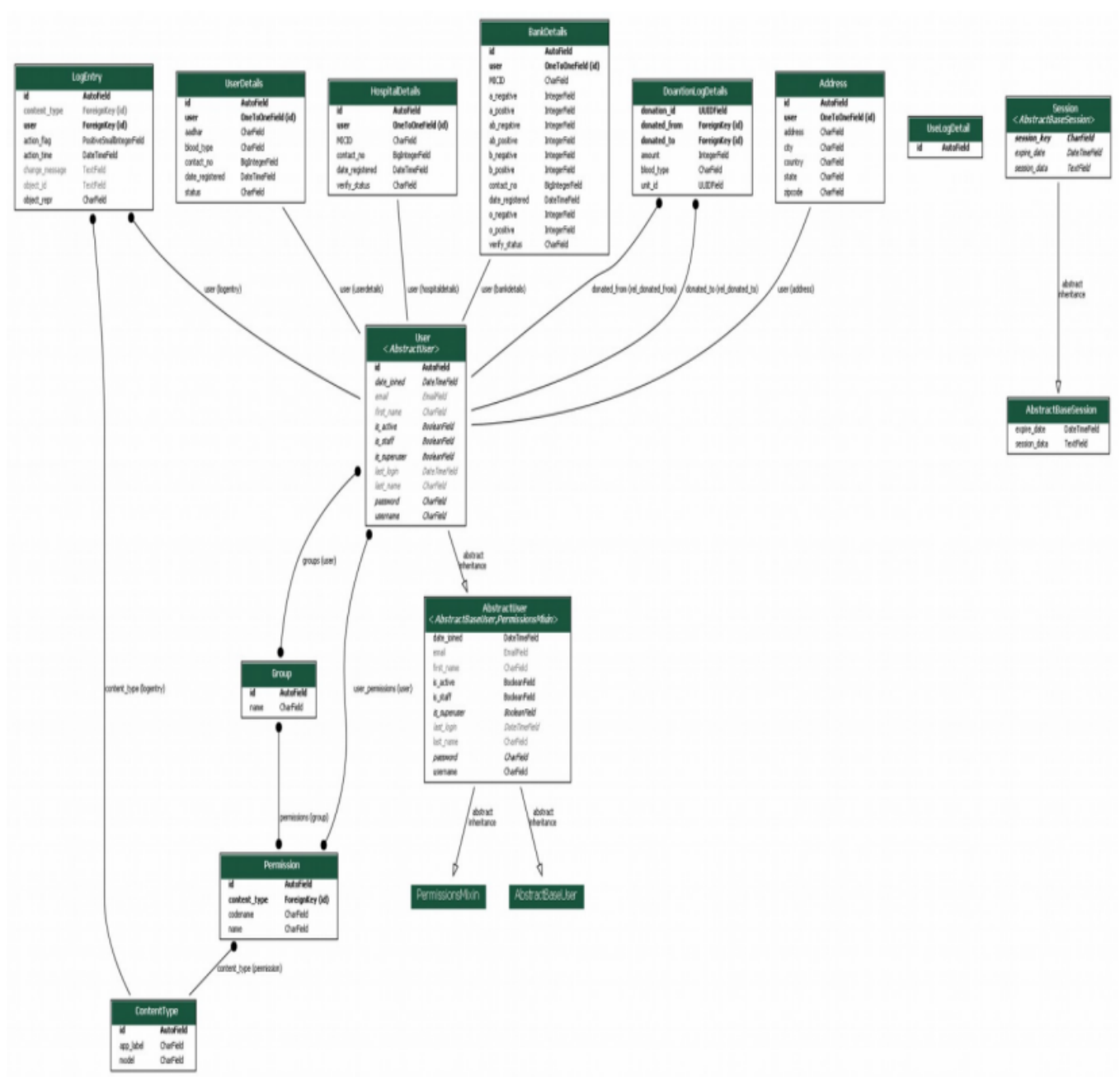

\section{RESULTS AND ANALYSIS}

In this section we show the results of our Realtime Blood Bank Data Repository model. Based on the analysis of information, database creation tables, division of modules, code the system results in the following screen's layout.

\section{DISCUSSION}

For the transition from paper based to electronic health record to be successful requires careful coordination, from implementation and selection to maintenance and training. A computerized Realtime blood bank data repository system is obtained after various steps which resulted in a variety of specifications, shown as screens. The privacy screen is a major specification that facilitates users to save their entered information. Flexibility of system is an important facility which helps in adding more users and benefit when using Computerized Realtime Blood Bank 


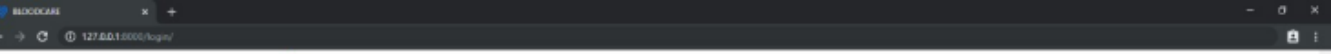

के BloodCare

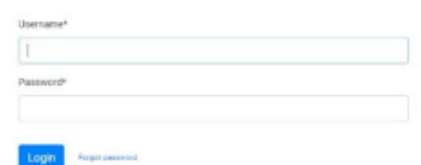

toon

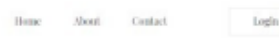

Figure 1 Login Page

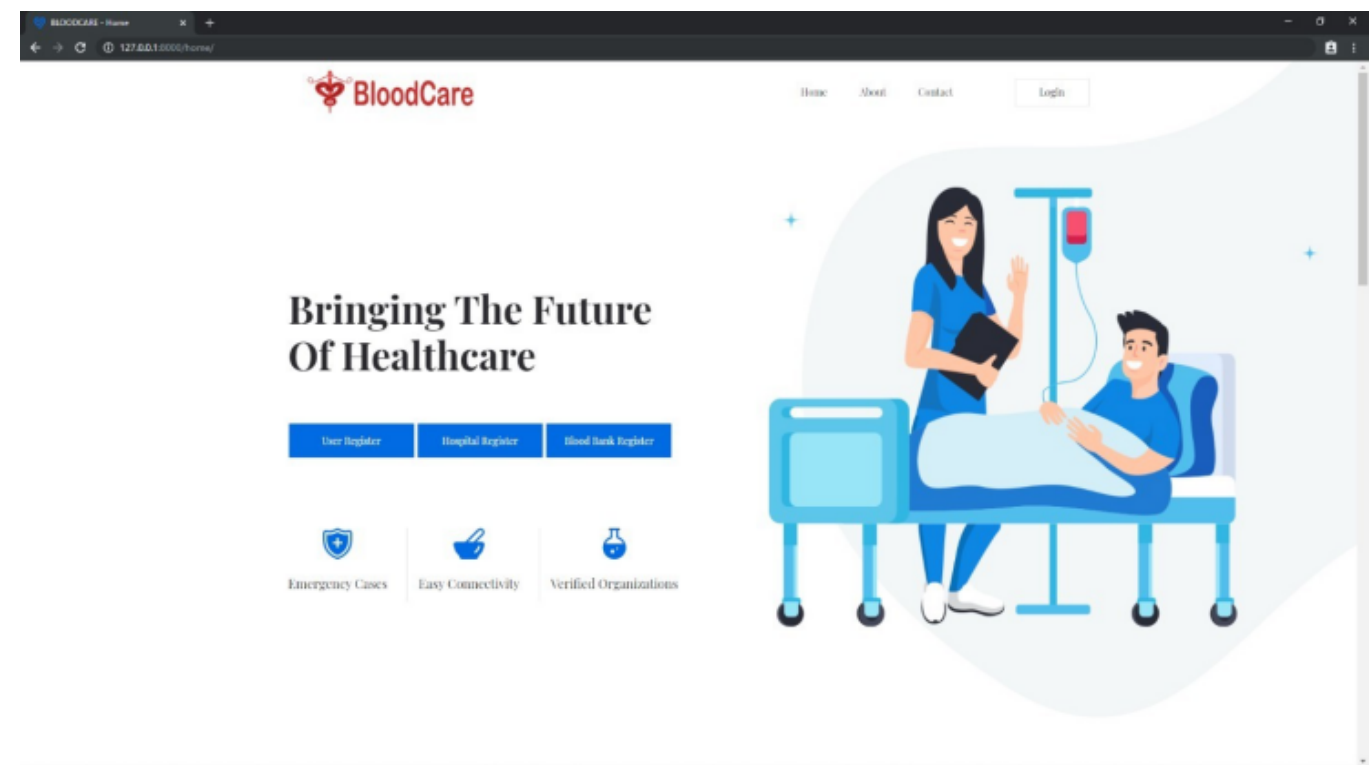

Figure 2 Home Page 


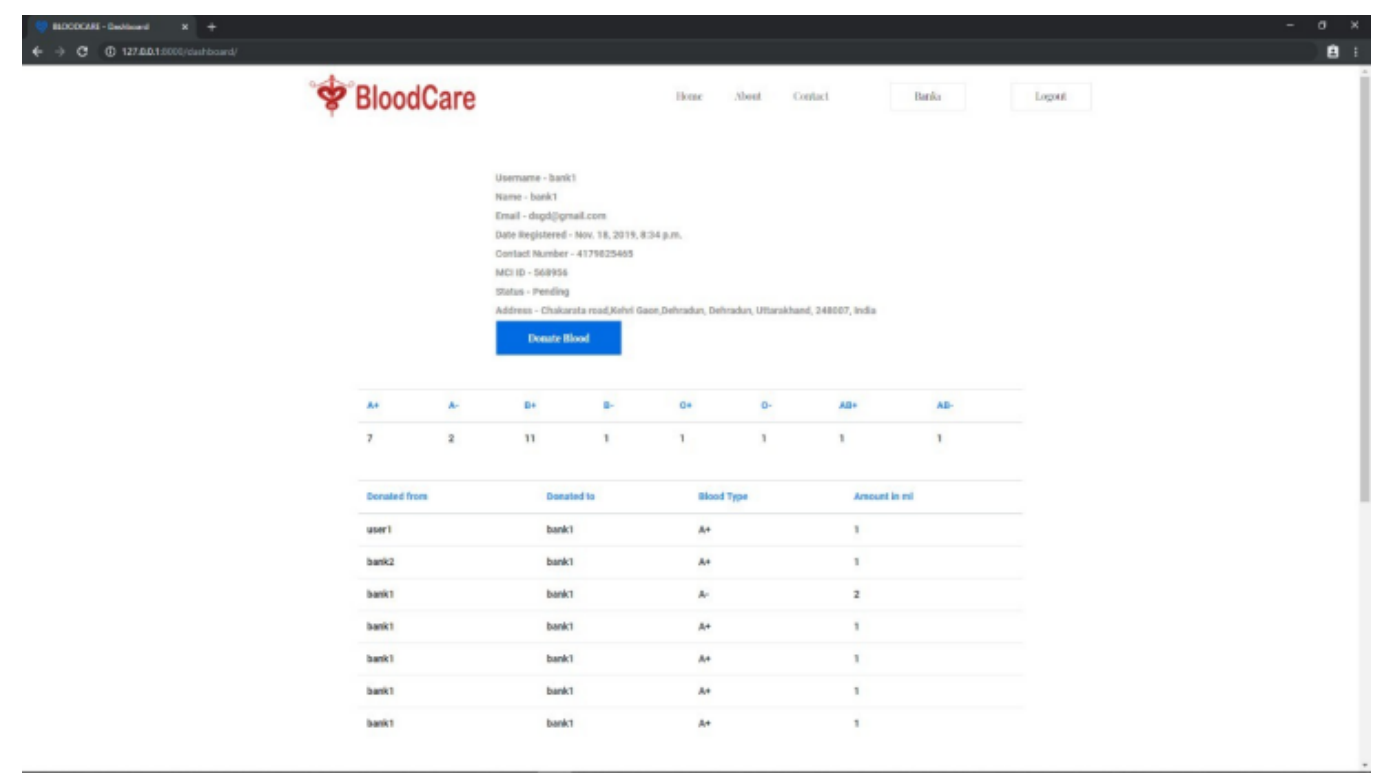

Figure 3 Blood Bank Dashboard

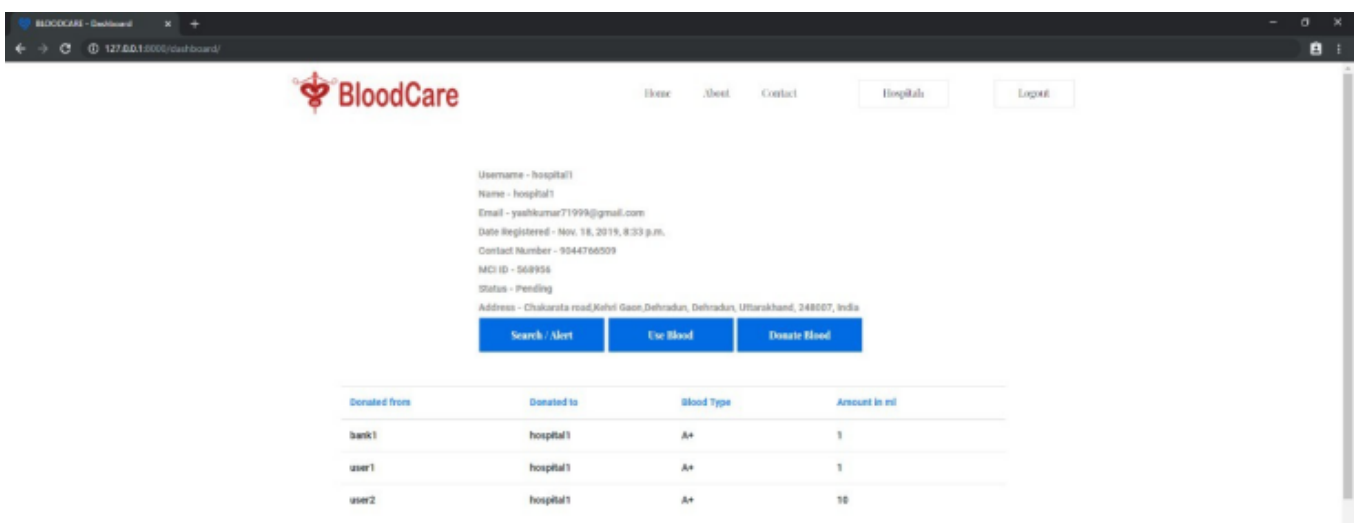

Figure 4 Hospital Dashboard 
Data Repository System, this also helps in sharing of different subunits. The system creates an integrated information domain where all the data of donor, compatibility of blood groups is available. As the world is directing towards new technologies, in a similar way this computerized system guarantees and ensures that every information entered to the system is valid to avoid errors. From the functionality point of view, the system ensures that less time is consumed, and from an economic point of view it minimizes the manpower, resulting in less expenses.

\section{CONCLUSION}

All in all, Computerized Realtime Blood Bank Data Repository System (CRBBDRS) may be a system that wants to control and manage all activities in bank departments. The system records nad keeps all donor information, distribution of blood to hospitals, blood information etc. The implementation of the system was carried out in many steps. The system was designed by creating a database and connecting it with the programming language code which ends up in the system screens layout. The system also leads to meeting user requirements. In general, this project designs only a prototype of the Computerized Realtime Blood Bank Data Repository System (CRBBDRS). This system has flexibility to modify itself and satisfy all needs to reach and cover up other departments as well, that is not currently covered here.

\section{REFERENCES}

Fawze, A. I., Mohammad, T. A., \& Z, M. I. (2015). "CBBR Centralized Blood Bank Repository". International Journal of Information System and Engineering, 3(1). 10.24924/ ijise/2015.11/v3.iss1/85.97

Fawze, I., \& Author, A. (n.d.). Centralized Blood Bank Repository Implementation with Java /JSP and Integrated with mobile app using phonegap (Case Study on Developing countries ).

Kebede, G. (2016). Designing a Web-Based Blood Bank Information Management System for the National Blood Bank of Ethiopia. M.Sc thesis. Addis Ababa University. Addis Ababa Ethiopia.

Mohammed, Y., \& and, Y. E. H. S. O. (n.d.). Computerized Central Blood Bank Management System (CCBBMS). In and others (Ed.), International Conference on Computer, Control, Electrical, and Electronics Engineering (ICCCEEE).

NATIONAL GUIDELINES ON SCREENING DONATED BLOOD FOR TTIs. (2013). Publications of the World Health Organization, version 1.

Nzoka, M., \& Ananda, F. (2014). Blood Bank Management Information System A Case Study of the Kenya National Blood Transfusion Services.

5 (May).

Yank, K. (2004). Build Your Own Database Driven Website Using PHP \& MySQL. 3rd ed M. Young, The Technical Writer's Handbook. Mill Valley, CA: University Science, 1989. In Build Your Own Database Driven Website Using PHP \& MySQL. Mill Valley, CA: University Science. 